\title{
在自然资源管理中发挥地理信息科技创新作用研究
}

\author{
陈伟军 \\ 广西壮族自治区测绘地理信息档案资料馆 \\ DOI:10.32629/gmsm.v2i5.371
}

[摘 要] 地理信息科技创新不仅能够为多个行业提供技术保障,合理利用地理信息科技创新成果对能够最大的发挥自然资源 管理效果。在应用地理信息科技创新成果的过程中,通过深入探测自然资源的过程,在发现其分布规律的同时,也能够提升自然 资源管理水平以及实际的工作效率。本文简述了当下自然资源管理工作面临的挑战,并就在地理信息科技创新基础上的自然 资源管理中的各个工作环节的创新服务进行了分析。

[关键词] 自然资源; 地理信息; 科技创新

对于自然资源管理工作来说, 最为重要的就是地理信息 科技创新, 其不仅能够提升自然资源管理工作的执行效率, 还能够在理清资源分布规律的同时, 为管理工作提供法理以 及重要的逻辑依据。因此, 想要做好自然资源管理工作, 首先 需要保证地理信息科技创新效果, 以此为基础提高自然资源 带来的社会效益, 为国家的经济增长以及行业的后续发展打 下基础。

1 自然资源管理工作的主要内容以及地理信息科技创 新的现状

1. 1自然资源管理工作内容

自然资源由于其社会性质使得其具有多种属性, 包括资 源、资本以及资产属性, 其创造的经济价值决定了其特殊属 性对于社会发展的意义。其不仅为社会提供了空间载体, 也 在保证人们物质甚至精神文化基础的同时, 从某些角度表现 出了产权关系。自然资源由于其特殊的分布规律和自然特征, 使得其蕴含着较为重要的生态价值以及为社会创造的经济 价值 ${ }^{[1]}$ 。从目前的实际情况来看, 自然资源保护工作主要包 括生态环境维持、空间分布规律以及了解资源数量等。在此 基础上延伸出的工作还包括评估自然资源状态与确定自然 资源的产权归属等。自然资源保护涉及的范围较广, 其在对 生态进行保护性修复的同时, 也为自然资源管理工作提供了 强大的技术保障, 并通过完善的管理机制提升自然资源管理 水平。

监测评价自然资源是自然资源管理工作中的重要工作 环节, 包括组织并实时监测、调查自然资源分布规律及情况以 及根据监测结果制定自然资源管理标准等, 通过将监测结果 进行进一步的汇总、整理以及分析, 不仅是为后续的结果使用 过程打下基础, 也是监测评估机制建立的重要条件 ${ }^{[2]}$ 。权属登 记工作同样是自然资源管理工作中的重要环节, 包括不动产 登记、自然资源归属产权登记、相关研究以及监测成果的运 用以及规范与制度的建立等, 是评估开采自然资源对环境的 影响以及计算对应承载力的关键环节。在保证生态环境符合 当下可持续发展战略的前提条件下建立监测预警机制是非 常有必要的, 能够更加科学合理的开发和利用自然资源。对
于普通民众来说, 节约自然资源、加紧生态空间布局是秀谷 桑前恶劣环境形势的效果实现前提。

\section{2 自然资源管理地理信息技术创新面临的挑战}

做好资源管理工作的基础是构建一个完善的修复系统 和管理体系, 通过其中的调查与评估环节充分发挥出自然资 源管理工作的实效性。不仅如此, 自然资源管理工作的工作 流程完善同样对于地理信息技术创新有一定的促进作用, 是 当下地理信息技术创新的重要发展机遇, 但在带来机遇的同 时, 也由于政策以及自然管理工作涉及的工作领域较广面临 着较多挑战。

首先是在地理信息技术应用过程中, 由于自然资源管理 工作涉及到的水、湖以及田地等部分隶属于同一部门进行管 理, 因此不仅要求工作人员全面了解自然管理机制的的应用 意义与工作流程, 还需要对应部门的管理人员掌握基础的有 关自然资源管理涉及到的各个部分的相关知识, 包括水利、 土地、林业以及农业等, 专业技能的水平提升是保证自然资 源管理工作实效性的前提 ${ }^{[3]}$; 其次, 地理信息技术在不断的 应用实践中得到了更新, 但同时也在后续应用这些创新成果 时有一定的约束条件, 这主要体现在数据应用于某些需要对 监测成果进行保密的要求是互相冲突的。为此, 我们的地理 信息技术人员应在考虑地理信息价值发挥的同时, 保持地理 信息推广与有关保密要求的平衡, 这也是目前地理信息行业 面临的主要问题; 第三, 由于地理信息技术的应用条件比较高, 每一条创新成果都需要技术人员投入大量的精力。但从目前 的实际情况来看, 数据属性并不具有广泛性与全面性, 这就导 致投入大量人力物力的创新成果实际应用效果较差 ${ }^{[4]}$ 。也正 是由于这种情况, 使得地理信息技术不能发挥其真正价值, 从而限制了地理信息行业的后续发展, 不利于自然资源管理 工作的展开。

\section{2 自然资源管理中地理信息技术的创新服务}

地理信息技术与自然资源管理中的各个工作环节之间 的联系较为密切, 对涉及到的经济、环境与创造的社会价值 均有一定的促进作用, 包括资源监测与调查、生态环境的修 复以及土地分配优化。因此, 相关部门的管理人员与实际进 
行操作的工作人员应重视地理信息技术创新对于自然资源 管理的重要意义, 在不断完善工作流程的基础上提升自身的 服务质量。

\section{1 构建自然资源监测调查技术体系}

体系的构建是工作进行的基础, 对于自然资源管理工作 来说更应该发挥地理信息技术创新优势,在国家相关政策的 支持下对现有的监测调查技术体系进行完善, 以保证自然资 源管理的工作效果。具体包括自然资源的归属权登记、技术 研发与应用资格以及资源调查等, 都需要按照监测调查技术 体系的相关要求展开后续工作。而如何将地理信息技术融入 到自然资源管理的工作过程中就成为了一个重要问题, 需要 充分利用自然资源综合管理以及要素管理测绘规范的支撑 特征, 以达到技术在资源管理工作中的应用效果 ${ }^{[5]}$ 。技术的 应用种类包括涉及到湖、林以及田等各个部分的全部技术与 动态数据、要素控制技术以及多要素关键监测技术等, 应用 目的是为了简化数据的分类过程, 并实现动态建模与控制质 量的技术应用效果。另外, 对于相关检查标准进行研究同样 十分重要。作为主要的自然资源要素的调查技术, 实际的应 用意义不仅在于其是多个部门通过研究共同制定的标准, 也 是提升资源管理工作效果的关键技术环节。但由于制定标准 受当地区域的影响较大, 因此目前还没有统一导致工作过程 不符合实际要求的现象较多。

\section{2 自然资源权属登记管理技术服务创新}

自然资源的权属登记环节一直以来都是资源管理工作 的关键点, 同时也是自然资源转化为自然资产所必须要遵循 的前提条件。由于自然资源范围以及相关关系的确定涉及到 较多部门与工作过程, 以此需要在探讨自然资源能够发挥最 大价值的基础上, 制定对应的权属核实制度才能够保证自然 资源的权属登记环节符合实际需求 ${ }^{[6]}$ 。可以考虑建立一个具 有不动产登记、归属权调查以及权籍数据分析作用的信息管 理平台。这样不仅能够发挥地理信息技术创新的实际效果, 也能完善现有的资产质量评估技术体系, 实现资产核算评估 的智能化与计算过程的自动化, 从而保证在地理信息技术创 新的社会环境下不断提升资源管理的工作效果。
2. 3构建国土空间规划技术创新服务体系

由于目前的地理信息技术在应用后产生的数据分析的 精度比较低, 因此当下解决空间规划数据冲突问题依然以人 工校对为主。因此,应利用已经趋于完善的地理信息创新技 术, 将其融入到实际的国土空间规划过程中, 在提升服务质 量的同时, 也能够发挥出自然资源的管理效果 ${ }^{[7]}$ 。其次, 应用 相关技术的同时应考虑到我国的区域特点。由于我国的各地 区的地形特征较为明显, 因此国土开发程度差异也比较大, 需要在建立对应指标体系的同时, 制定不同区域下的资源环 境承载能力评估方案, 以符合实际的工作需求。

\section{3 结语}

综上所述, 地理信息技术的创新与应用对于资源管理工 作的效果发挥有着十分重要的作用。在提高自然资源管理的 工作效率的基础上, 还能够通过多技术的融合过程以及多体 系的构建进一步完善自然自然资源管理的工作流程, 这也是 目前自然资源管理工作的服务质量不断提升的重要原因。相 信未来在不断对地理信息技术进行创新的过程中, 能够进一 步提高技术的应用水平, 从而保证自然资源管理的应用效果 的持续提高。

\section{[参考文献]}

[1]桂德竹,程鹏飞,文汉江.在自然资源管理中发挥测绘地理信息 科技创新作用研究[J].武汉大学学报(信息科学版),2019,(1):97-100.

[2]菅贞贞.土地测绘中地理信息系统的应用研究 [J].科 技创新导报,2017,(24):140-141.

[3] 吴登华,王懿祥,孙朝辉.基于GIS的古树名木巡护APP 设计与开发[J].林业资源管理,2018,(3):141-145.

[4]苏布德,赵洋毅,王克勤. 基于GIS的滇南踏青河源头小 流域近20年土壤侵蚀变化[J].林业资源管理,2018,(6):90-98.

[5]胡勇,江冰婷.地理国情普查在自然资源资产负债表 编制的应用思考 [J]. 国土资源科技管理,2018,(1):112-118.

[6]张峰.地理国情监测在领导干部自然资源资产离任审计 工作中的应用探讨[J].测绘与空间地理信息,2017,(12):126-128.

[7]管雯君,杨传勇.自然资源部统筹下的新型地理设计 思路探索[J].规划师,2018,(12):68-72. 